\title{
Delayed Pulmonary Apoptosis of Diet-Induced Obesity Mice following Escherichia coli Infection through the Mitochondrial Apoptotic Pathway
}

\author{
Fengyuan Wang $\mathbb{D}^{1},{ }^{1}$ Zhicai Zuo $\mathbb{D}^{1},{ }^{1}$ Zhuangzhi Yang, ${ }^{2}$ Kejie Chen ${ }^{(D)}{ }^{3}$ Jing Fang $\mathbb{D}^{1},{ }^{1}$ \\ Hengmin Cui $\mathbb{D}^{1},{ }^{1}$ Gang Shu, ${ }^{1}$ Yi Zhou, ${ }^{4}$ Yi Geng $\mathbb{D}^{1},{ }^{1}$ and Ping Ouyang ${ }^{1}$ \\ ${ }^{1}$ College of Veterinary Medicine, Sichuan Agricultural University, Chengdu, Sichuan 611130, China \\ ${ }^{2}$ Chengdu Academy of Agriculture and Forestry Sciences, Chengdu, Sichuan 611130, China \\ ${ }^{3}$ School of Public Health, Chengdu Medical College, Chengdu, Sichuan 610500, China \\ ${ }^{4}$ College of Life Science, Sichuan Agricultural University, Ya'an, Sichuan 625014, China
}

Correspondence should be addressed to Kejie Chen; ckj930@126.com and Jing Fang; fangjing4109@163.com

Received 25 March 2019; Revised 26 June 2019; Accepted 23 August 2019; Published 22 October 2019

Academic Editor: Juan C. Mayo

Copyright ( 2019 Fengyuan Wang et al. This is an open access article distributed under the Creative Commons Attribution License, which permits unrestricted use, distribution, and reproduction in any medium, provided the original work is properly cited.

Escherichia coli (E. coli) is one of pathogens causing nosocomial pneumonia and could induce pulmonary excessive apoptosis. Although much has been learned about metabolic diseases induced by obesity, the information linking bacterial pneumonia to obesity is limited. Accordingly, we investigated the apoptosis of normal (lean) and diet-induced obesity (DIO, fed a high-fat diet) mice after nasal instillation with E. coli. Lung tissues were obtained at 0 (preinfection), 12, 24, and $72 \mathrm{~h}$ after infection, and acute pulmonary inflammation was observed at $12 \mathrm{~h}$. Elevated cell apoptosis and percentage of pulmonary cells depolarized with collapse of the mitochondrial transmembrane potential $(\Delta \psi \mathrm{m})$ occurred in response to bacterial infection. The relative mRNA and protein expressions of Bax, caspase-3, and caspase-9 increased, but Bcl-2 decreased in the lung. Interestingly, the apoptotic percentage and most of apoptosis-associated factors mentioned above peaked at 12 or $24 \mathrm{~h}$ in the lean-E. coli group, while at 24 or $72 \mathrm{~h}$ in the DIO-E. coli group. Taken together, these findings indicated that the E. coli pneumonia caused excessive pulmonary apoptosis through the mitochondria-mediated pathway, and the apoptosis was delayed in the DIO mice with E. coli pneumonia.

\section{Introduction}

Obesity has developed into a considerable health problem in the whole world. Obese people are under threat of respiratory symptoms, even with no obvious respiratory illness [1], and may have an increased risk of pneumonia [2]. The adverse effects of obesity on the respiratory system, like increasing airway resistance and the work of breathing, impairing respiratory muscle function and gas exchange [3], are mediated by a number of mechanisms, including production of proinflammatory cytokines by adipose tissue, mechanical restriction of thoracic volumes, and obesity-induced hypoventilation [4]. As mentioned above, obese individuals are more susceptible to pneumonia, but paradoxically, improved outcomes, like reduced mortality, are noticed in studies of acute bacterial pneumonia among obese ones [5-7].
Apoptosis has been recognized and accepted as a distinctive and important mode of "programmed" cell death [8]. As described in the literature, oxidative stress could cause cell apoptosis via both the mitochondria-dependent and mitochondria-independent pathways [9]. Reactive oxygen species (ROS), one of the most important products during oxidative stress, is a collective of oxygen-derived free radicals, which is produced by uncoupling, disturbance, or inhibition of mitochondrial respiratory chain. High ROS exposure gives rise to oxidative damage to mitochondrial DNA which consequently induces cell apoptosis [10]. Meanwhile, ROS is supposed to be involved in obesity [11]. A link between nutritional status and apoptosis reveals that high caloric intake may impair mitochondria for apoptosis [12]. Moreover, inflammation is a cellular response to stress, injury, or infection [13]. During infection, cells undergo 
apoptosis to inhibit the spread of microbes by directly killing or depriving the cellular resources for survival and replication $[14,15]$. While screening these findings, although a new insight into the link between obesity and infection was provided, it is not clear whether cell apoptosis is involved.

We recently carried out experiments, in which dietinduced obesity (DIO) mice presented a delayed inflammatory response and oxidative stress in nonfatal acute pneumonia induced by E. coli infection [16]. It is well known that inflammation and oxidative stress can induce apoptosis in theory. Since there is little known about how pulmonary cell apoptosis impacted on the lungs of DIO mice following acute bacterial pneumonia, we purchased ICR mice fed high-fat diets, and then instilled the mice intranasally with E. coli, to shed light on the variations of pulmonary cell apoptosis between the normal and DIO mice following acute bacterial pneumonia.

\section{Materials and Methods}

2.1. Animal Model of Obesity. Three-week-old male ICR mice were purchased from Dossy Animal Center (Chengdu, China) and housed under specific pathogen-free conditions. All animal experimental procedures were approved according to the National and International Guidelines and by Sichuan Agricultural University Animal Care and Use Committee (Approval No. 2012-024).

Mice received either a normal diet or a high-fat diet, obtained from Dossy Animal Center according to our previous study [17]. The content of fat, mainly coming from the lard and soybean oil, was about $7 \%$ in the normal diet or $35.2 \%$ in the high-fat diet, respectively [18]. Food and water were supplied ad libitum. After feeding high-fat diets for 8 weeks, mice were weighed, and the ones whose obese index exceeded $20 \%$ were defined as successful obesity induction [19].

Obese index $=\frac{\text { individual weight of DIO }- \text { average weight of lean }}{\text { average weight of lean }} \times 100 \%$.

2.2. Groups and Pulmonary Infection Model. After feeding the high-fat diet for 8 weeks, the obese index of about $90 \%$ mice exceed $20 \%$. Then, the mice fed either normal diets or highfat diets were divided into 2 groups (144/group) as lean and DIO (diet-induced obese). The 2 groups were divided into 4 groups (72/group), namely, lean-E. coli, lean-uninfected, DIO-E. coli, and DIO-uninfected. Mice were sampled at $0 \mathrm{~h}$ (preinfection), $12 \mathrm{~h}, 24 \mathrm{~h}$, and $72 \mathrm{~h}$ after E. coli infection.

Escherichia coli was obtained from the Veterinary Medical Laboratory of Sichuan Agricultural University (Ya'an, China), and the highest homologous with anthropogenic U00096 E. coli was cultured in Luria-Bertani broth at $37^{\circ} \mathrm{C}$ for 18 hours. Then, the bacterial culture was centrifuged, and bacterial pellets were resuspended in PBS to produce the inoculums. After being anesthetized with ether, mice in the lean-E. coli or DIO-E. coli group were instilled intranasally with $40 \mu \mathrm{L}$ inoculum of $E$. coli (containing approximately $4 \times 10^{9}$ colony-forming units) suspended in phosphate-buffered saline (PBS) as reported previously
[20]. And the same amount of PBS was given to the mice in the lean-uninfected or DIO-uninfected group by the same method.

2.3. Lung Injury Assayed by Histopathology. After infection with $E$. coli for $12 \mathrm{~h}$, the lungs of eight mice from each group were immediately fixed in $4 \%$ paraformaldehyde and then dehydrated in alcohol, embedded by paraffin, sectioned at $5 \mu \mathrm{m}$, and processed for hematoxylin and eosin staining. Histopathological changes were observed and photographed with a digital camera under 200x and 400x magnifications (Nikon DS-Ri1, Japan).

2.4. Measurement of Cell Apoptosis by Flow Cytometry. At indicated time point, the lungs from eight mice in each group were sampled and prepared into the single-cell suspension at a concentration of about $1 \times 10^{6}$ cells $/ \mathrm{mL}$. After fluorescence staining by annexin $\mathrm{V}$-fluorescein isothiocyanate (V-FITC) and propidium iodide (PI) at room temperature for $15 \mathrm{~min}$ in the dark, the cells were resuspended with annexin binding buffer, and the percentage of apoptotic cells was assayed by a flow cytometer (BD FACSCalibur) within $1 \mathrm{~h}$. The annexin V-FITC kit was obtained from BD Pharmingen (559763, USA).

\subsection{Measurement of Mitochondrial Transmembrane} Potential $(\Delta \psi \mathrm{m}) .0 .5 \mathrm{~mL}$ single-cell suspension prepared above (containing about $5 \times 10^{5}$ cells) was cultured with JC-1 working solution at $37^{\circ} \mathrm{C}$ for $20 \mathrm{~min}$ under a $5 \%$ $\mathrm{CO}_{2}$ incubator. After washing and suspending with JC-1 assay buffer, the mitochondrial membrane potential was assayed by a flow cytometer. The JC-1 kit was obtained from BD Pharmingen (USA, 551302).

2.6. Quantitative Real-Time PCR. At indicated time points, the lungs from eight mice in each group were crushed into powder with liquid nitrogen. Total RNA was prepared from TRIzol (9108/9109, Takara, Otsu, Japan) according to the manufacturer's recommendation, reverse transcribed with random hexamers (Prim-Script ${ }^{\mathrm{TM}}$ RT reagent Kit, RR047A, Takara, Japan), and amplified with specific primers. The primers were designed using Primer 5 software or NCBI primer pick online (Table 1) and synthesized at Sangon Biotech (Shanghai, China). The expression of caspase-3, caspase-9, Bax, and $\mathrm{Bcl}-2$ transcript is shown relative to that of $\beta$-actin using the $2^{-\Delta \Delta \mathrm{CT}}$ method.

2.7. Western Blotting. The tissue proteins were extracted with RIPA lysis buffer. After being equalized for total protein concentration, the protein was separated by SDS-PAGE and subjected to semidry blotting onto nitrocellulose membranes. The membrane was blocked and incubated overnight with rabbit anti-mouse caspase-3, caspase-9, Bax, Bcl-2, and GAPDH antibodies (ab32503, ab182858, ab184787, and ab202068, Abcam; 5174, Cell Signaling Technology) at $4^{\circ} \mathrm{C}$. After being incubated with the peroxidase-conjugated goat anti-rabbit IgG (7074, Cell Signaling Technology), the blot was visualized by $\mathrm{ECL}^{\mathrm{TM}}$ (P0018A, Beyotime Technology) and X-ray film. Then, the expression of apoptosis- 
TABLE 1: Sequence of primers used in qRT-PCR.

\begin{tabular}{lccc}
\hline Target gene & Accession number & Primer sequence $\left(5^{\prime}-3^{\prime}\right)$ & Product size \\
\hline Caspase-3 & NM_009810.3 & $\begin{array}{c}\text { Forward: ACATGGGAGCAAGTCAGTGG } \\
\text { Reverse: CGTCCACATCCGTACCAGAG }\end{array}$ \\
Caspase-9 & NM_015733.5 & $\begin{array}{c}\text { Forward: GAGGTGAAGAACGACCTGAC } \\
\text { Reverse: AGAGGATGACCACCACAAAG }\end{array}$ \\
Bax & Forward: ATGCGTCCACCAAGAAGC & Reverse: CAGTTGAAGTTGCCATCAGC \\
Bcl-2 & NM_007527.3 & Forward: AGCCTGAGAGCAACCCAAT & 103 bp \\
$\beta$-Actin & NM_009741.5 & $\begin{array}{c}\text { Reverse: AGCGACGAGAGAAGTCATCC } \\
\text { Forward: GCTGTGCTATGTTGCTCTAG } \\
\text { Reverse: CGCTCGTTGCCAATAGTG }\end{array}$ \\
\hline
\end{tabular}

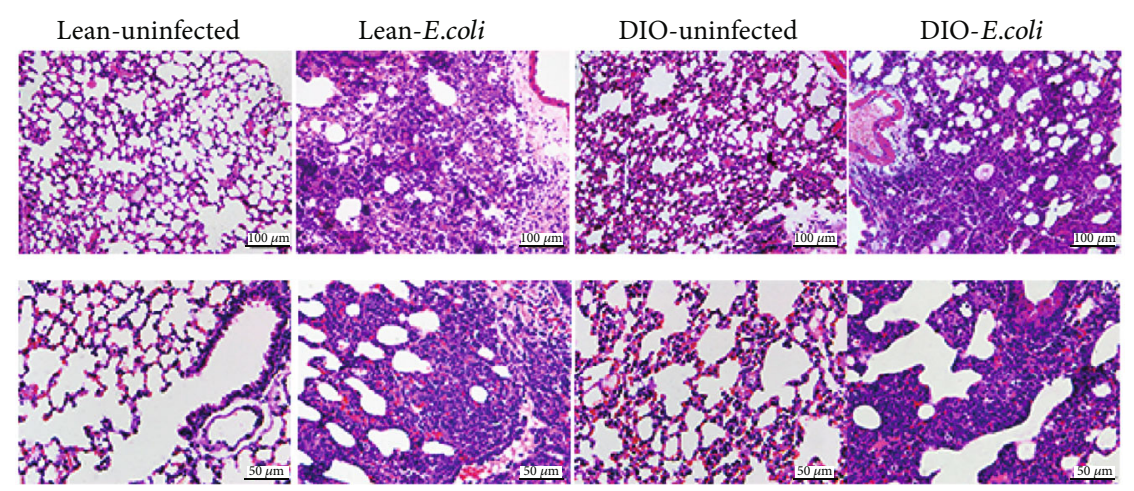

Figure 1: The representative histopathological changes of the lung at $12 \mathrm{~h}$ after infection. HE staining. Scale bars $=50 \mu \mathrm{m}(400 \mathrm{x})$ or $100 \mu \mathrm{m}(200 \mathrm{x})$.

associated proteins is shown relative to that of GAPDH using Quantity One software.

2.8. Immunohistochemistry. The paraffin sections were treated with $3.0 \%$ hydrogen peroxide followed by boiling sodium citrate solution and incubated overnight with rabbit anti-mouse primary antibodies against caspase-3, caspase-9, $\mathrm{Bax}$, and $\mathrm{Bcl}-2$ at $4^{\circ} \mathrm{C}$. Then, the sections were executed with SABC methods (SA1020, Wuhan Boster Bio-Engineering Limited Company, China) and visualized by DAB. Finally, the stained sections were photographed with a digital camera under 1000x magnification (Nikon DS-Ri1, Japan).

2.9. Statistical Analysis. The SPSS 17.0 statistical software package program for Windows was used for statistical tests. All results were expressed as the mean \pm standard deviation. The significant differences among the four groups were analyzed by variance analyses (LSD or Dunnett's T3). A value of $p<0.05$ was accepted as a statistically significant difference. The change rate was calculated by the following formula, and DIO and lean in the figures indicated the change rate of DIO and lean mice, respectively.

Change rate $(\%)=\frac{\text { value of infected mice }- \text { value of uninfected mice }}{\text { value of uninfected mice }} \times 100 \%$.

\section{Results}

3.1. Pathological Injuries of the Lung following E. coli Infection. As shown in Figure 1, the lung exhibited typical acute inflammation in either the lean- or DIO-E. coli group at $12 \mathrm{~h}$ after infection. Many neutrophils infiltrated into the bronchioles and alveolar lumen. Moreover, hyperaemia and hemorrhage of the alveolar wall were observed, as well as adjacent alveolar fusion and compensatory enlargement.

3.2. Changes in the Percentages of Apoptotic Cells in the Lung following E. coli Infection. As shown in Figure 2(a), cells in the left lower quadrant represent apoptotic negative cells, and cells in the right lower or upper quadrant represent apoptotic cells at an early phase or a late phase, respectively. The changes in the percentage of apoptotic cells in the lung displayed a different tendency between the lean and DIO groups (Figure 2(b)). The percentage of apoptotic cells in the lean-E. coli group was significantly higher $(p<0.05)$ than that in the lean group only at $12 \mathrm{~h}$ and $24 \mathrm{~h}$, while the value in the DIO-E. coli group was significantly higher $(p<0.05)$ than that in the DIO-uninfected group from $12 \mathrm{~h}$ to $72 \mathrm{~h}$. Moreover, the line chart (Figure 2(c)) showed that the change rate of apoptotic cell percentage in the lean mice peaked at $12 \mathrm{~h}$, while that in the DIO mice continued to rise to $72 \mathrm{~h}$.

3.3. Effect of Mitochondrial Transmembrane Potential ( $\Delta \psi m)$ in the Lung following E. coli Infection. The induction of 


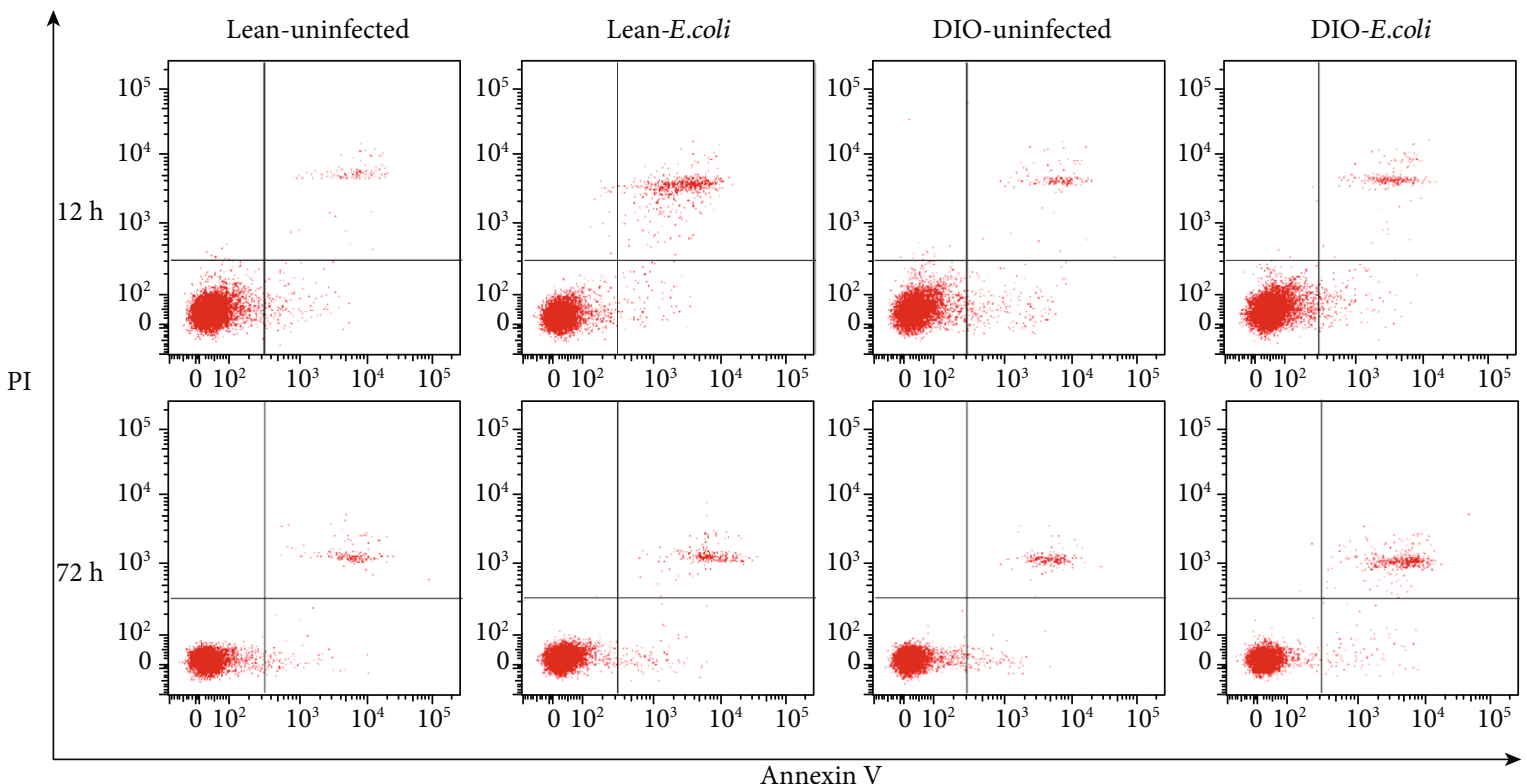

(a)

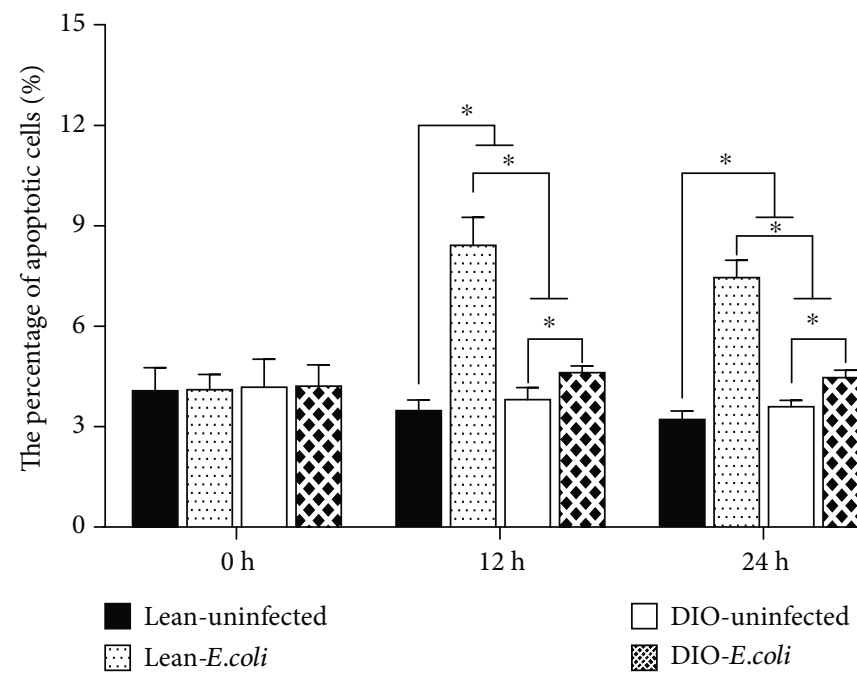

(b)

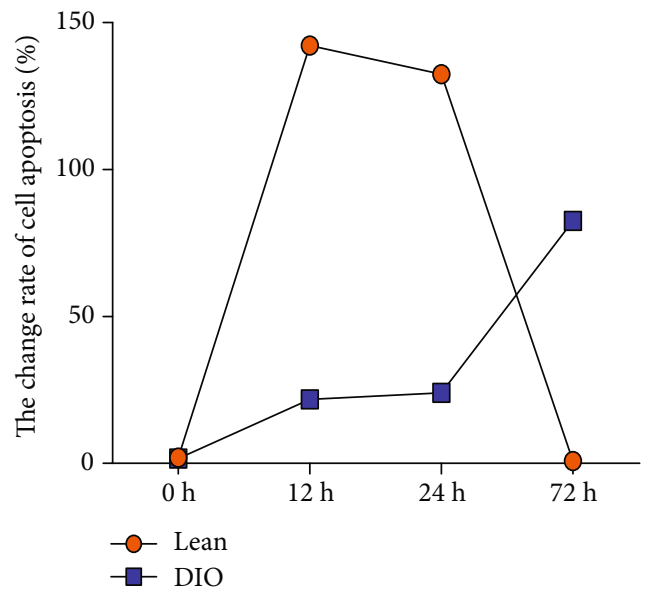

(c)

FIgURE 2: Apoptotic pulmonary cells. (a) Representative scattergrams of apoptotic pulmonary cells by flow cytometry at $12 \mathrm{~h}$ and $72 \mathrm{~h}$. (b) The percentages of apoptotic pulmonary cells $(\%)$. (c) The change rates of pulmonary cell apoptosis $(\%) .{ }^{*}$ The significant difference $(p<0.05)$. 
apoptosis was associated with the perturbation of mitochondrial functions. Here, the changes in $\Delta \psi \mathrm{m}$ were examined using fluorescent dye JC-1. Cells in the right upper quadrant represent high electronegativity, and cells in the right lower quadrant represent low electronegativity (Figure 3(a)). As shown in Figures 3(a) and 3(b), the percentages of pulmonary cells depolarized with collapse of $\Delta \psi \mathrm{m}$ were significantly increased $(p<0.05)$ in the lean-E. coli group from $12 \mathrm{~h}$ to $72 \mathrm{~h}$ compared with the lean-uninfected group. However, the values in the DIO-E. coli group were higher only at $24 \mathrm{~h}$ and $72 \mathrm{~h}(p<0.05)$ than those in the DIO-uninfected group. The change rate of decreased $\Delta \psi \mathrm{m}$ of pulmonary cell was similar to the change rate of apoptotic percentage (Figure 3(c)).

3.4. Changes in Bax, Bcl-2, Caspase-3, and Caspase-9 Relative $m R N A$ Expressions in the Lung following E. coli Infection. In the lean-E. coli group, the mRNA expression levels of Bax and caspase- 9 were significantly increased $(p<0.05)$ at $12 \mathrm{~h}$ and $24 \mathrm{~h}$ and caspase- 3 from $12 \mathrm{~h}$ to $72 \mathrm{~h}$ in comparison to the lean-uninfected group, while $\mathrm{Bcl}-2$ was significantly decreased $(p<0.05)$ at $12 \mathrm{~h}$. When compared with those of the DIO-uninfected group, the Bax mRNA levels of the DIO-E. coli group were all significantly increased at $72 \mathrm{~h}$, as well as caspase- 3 and caspase- 9 at $24 \mathrm{~h}$ and $72 \mathrm{~h}(p<0.05)$, while Bcl-2 was significantly decreased $(p<0.05)$ only at $72 \mathrm{~h}$ (Figures 4(a)-4(d)).

Among the four groups, the lean-E. coli group exhibited the highest ratio of $\mathrm{Bax} / \mathrm{Bcl}-2$ at $12 \mathrm{~h}$ but the DIO-E. coli group at $72 \mathrm{~h}$ (Figure $4(\mathrm{e}))$. As exhibited by the line chart (Figures $4(\mathrm{f})$ and $4(\mathrm{~g})$ ), the change rates of these apoptotic regulators were the highest in the lean mice at $12 \mathrm{~h}$, while the peak change rates in the DIO mice were delayed to $24 \mathrm{~h}$ or $72 \mathrm{~h}$.

\subsection{Changes in Bax, Bcl-2, Caspase-3, and Caspase-9 Relative} Protein Expression in the Lung following E. coli Infection. As shown in Figure 5, the relative protein expressions of Bax and caspase- 9 were significantly increased in the lean-E. coli group in comparison to the lean-uninfected group at $12 \mathrm{~h}$ $(p<0.05)$ and caspase- 3 at $12 \mathrm{~h}$ and $24 \mathrm{~h}$. Compared with the DIO-uninfected group, the caspase- 3 and caspase- 9 protein levels were significantly increased in the DIO-E. coli group at $24 \mathrm{~h}$ and $72 \mathrm{~h}(p<0.05)$ and Bax at $12 \mathrm{~h}$ and $72 \mathrm{~h}$ $(p<0.05)$. Furthermore, the Bcl-2 protein level was lower in the DIO mice than in the lean mice at $0 \mathrm{~h}(p<0.05)$. After infection, the Bcl-2 protein value declined at $12 \mathrm{~h}$ and $24 \mathrm{~h}$ in the lean-E. coli group and at $72 \mathrm{~h}$ in the DIO-E. coli group when compared with each uninfected control, respectively $(p<0.05)$.

The increased tendency of the $\mathrm{Bax} / \mathrm{Bcl}-2$ protein expression ratio was similar to its mRNA expression ratio (Figure 5(f)). Conclusively, the line chart of change rate showed that the apoptotic protein levels changed the most at $12 \mathrm{~h}$ in the lean mice but at $72 \mathrm{~h}$ in the DIO mice (Figures 5(g) and 5(h)).

3.6. Subcellular Localization of Bax, Bcl-2, Caspase-3, and Caspase-9 Proteins in the Lung. As shown in Figure 6, a few positive caspase- 9 proteins were observed on the alveolar wall in the lean- and DIO-uninfected groups. After infection, large numbers of positive caspase- 9 were visualized in the neutrophil-infiltrated areas or the alveolar wall in the leanand DIO-E. coli groups. The location of caspase- 3 protein was similar to that of caspase-9, but its content was lower than that of caspase-9. Bax-positive protein presented a scattered distribution, and a few Bax were seen in the alveolar wall of the uninfected groups, while there were more Bax in the neutrophil-infiltrated areas of the E. coli-infected groups. On the contrary, numerous Bcl-2-positive proteins appeared mainly in the epithelial cells of respiratory bronchioles in the uninfected groups but a few $\mathrm{Bcl}-2$ in the E. coli-infected groups.

\section{Discussion}

Escherichia coli is one of the possible etiologies of nosocomial pneumonia, as well as a strong inducer of proinflammatory cytokine production from alveolar macrophages [21]. In the present study, $10^{9} \mathrm{CFUs} / \mathrm{mL}$ E. coli was intranasally instilled in mice (either lean or DIO) to establish acute pneumonia. According to histopathological observation, a typical acute inflammation appeared in the lung with a large number of neutrophils infiltrating into the alveolar and bronchiolar lumen. When the inflammation occurred, these inflammatory cells produced various cytokines. Thus, after infection, the cytokine and adipocytokine levels were significantly increased in mice [16].

In bacterial infection, the host is mainly dependent on the selective phagocytosis of neutrophils to eliminate invaders [22]. Neutrophils are able to synthesize and secrete proinflammatory cytokines in response to a variety of inflammatory stimuli [23]. And some typical cytokines, like tumor necrosis factor- (TNF-) $\alpha$, interferon- (IFN-) $\gamma$, and interleukins (IL), can trigger cell apoptosis [24]. Moreover, neutrophil recruitment can activate the oxidative response, which is a primary host defense mechanism in acute pneumonia and a mediator of apoptosis $[25,26]$. In addition, the generation of reactive oxygen species (ROS) in oxidative stress is capable to induce mitochondrial DNA damage and trigger apoptosis [27]. Our previous experiments indicated that pulmonary oxidative stress was notable in the mice after nasal instillation with E. coli [16]. Above all, acute bacterial infections were fairly associated with apoptosis, and this study puts emphasis on the mitochondrial apoptosis pathway between the lean and DIO mice with acute E. coli pneumonia.

As mentioned above, bacteria play an important role in triggering apoptosis. The mechanism of apoptosis in pulmonary diseases has two main hypotheses, namely, "neutrophilic hypothesis" and "epithelial hypothesis" [28], which means that cell apoptosis in pneumonia happened in two cell types, neutrophils and epithelia. Extensive evidences of neutrophil and alveolar epithelial cell apoptosis have been described on bacterial pneumonia and lipopolysaccharide(LPS, one of the most important virulence factors of gram-negative bacteria) induced lung injury [29-31]. Besides, neutrophil regulates and alleviates inflammation through spontaneous apoptosis [32, 33]. In accordance with these researches, through flow cytometry, increased percentages of 


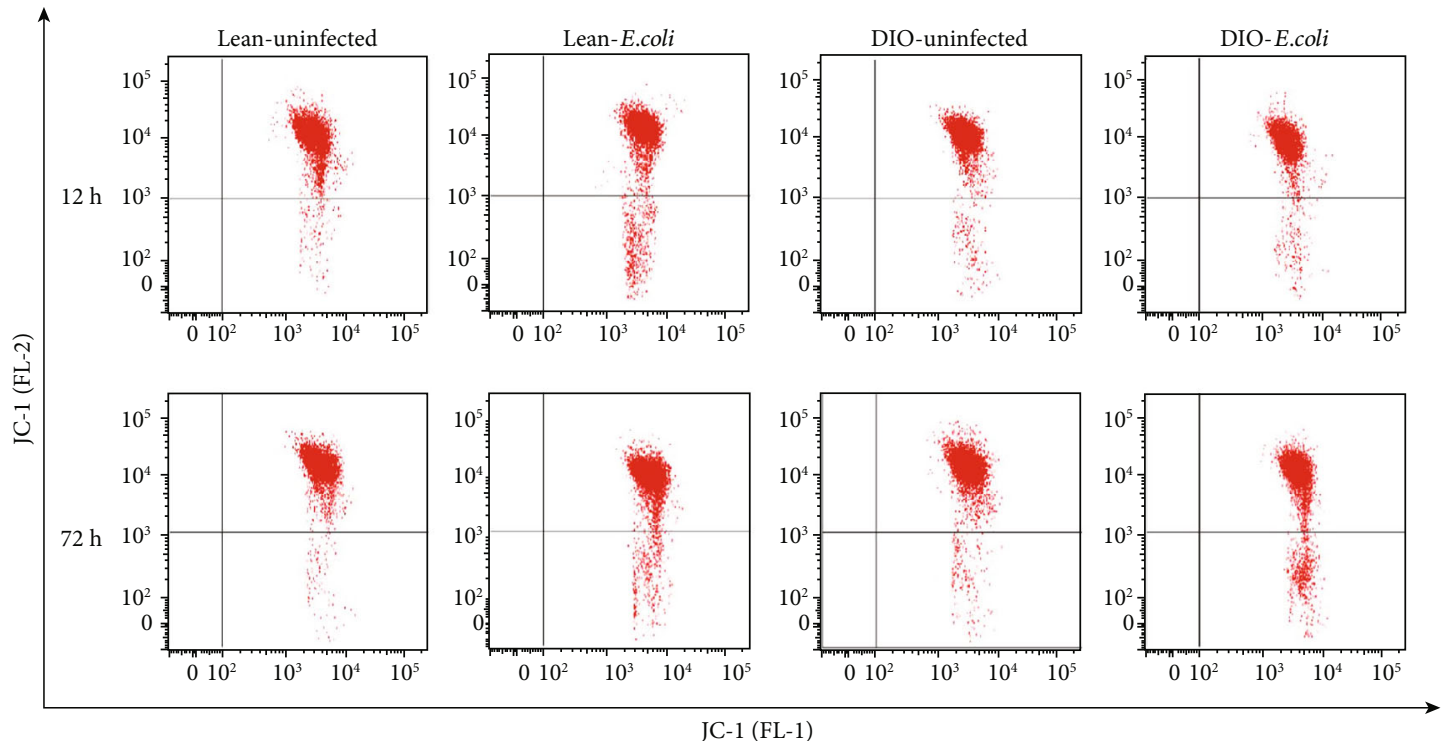

(a)
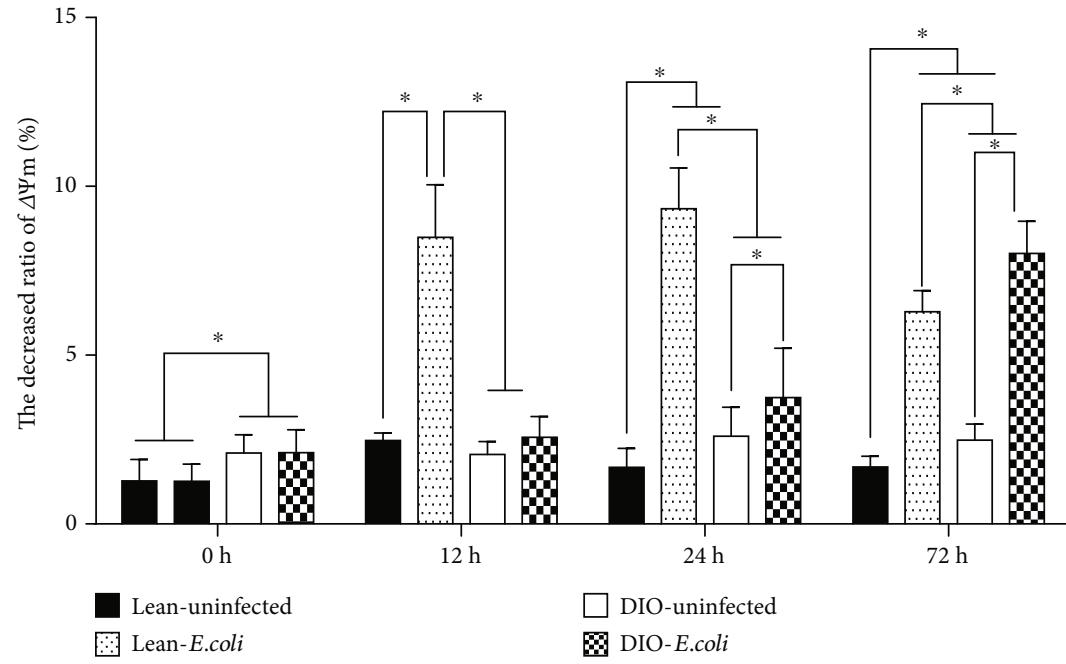

$\square$ DIO-uninfected

จ DIO-E.coli

(b)

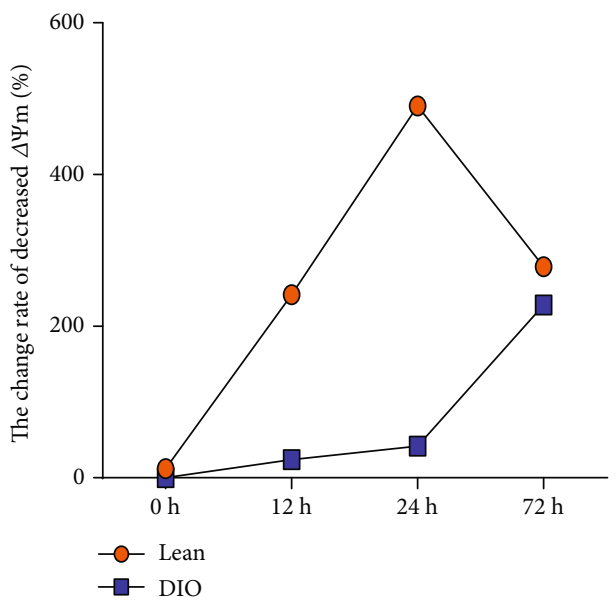

(c)

Figure 3: Pulmonary mitochondria transmembrane potential $(\Delta \psi \mathrm{m})$. (a) Representative scattergrams of reduced pulmonary $\Delta \psi \mathrm{m}$ by flow cytometry at $12 \mathrm{~h}$ and $72 \mathrm{~h}$. (b) The decreased ratios of pulmonary $\Delta \psi \mathrm{m}(\%)$. (c) The change rates of decreased pulmonary $\Delta \psi \mathrm{m}(\%) .{ }^{*} \mathrm{The}$ significant difference $(p<0.05)$. 


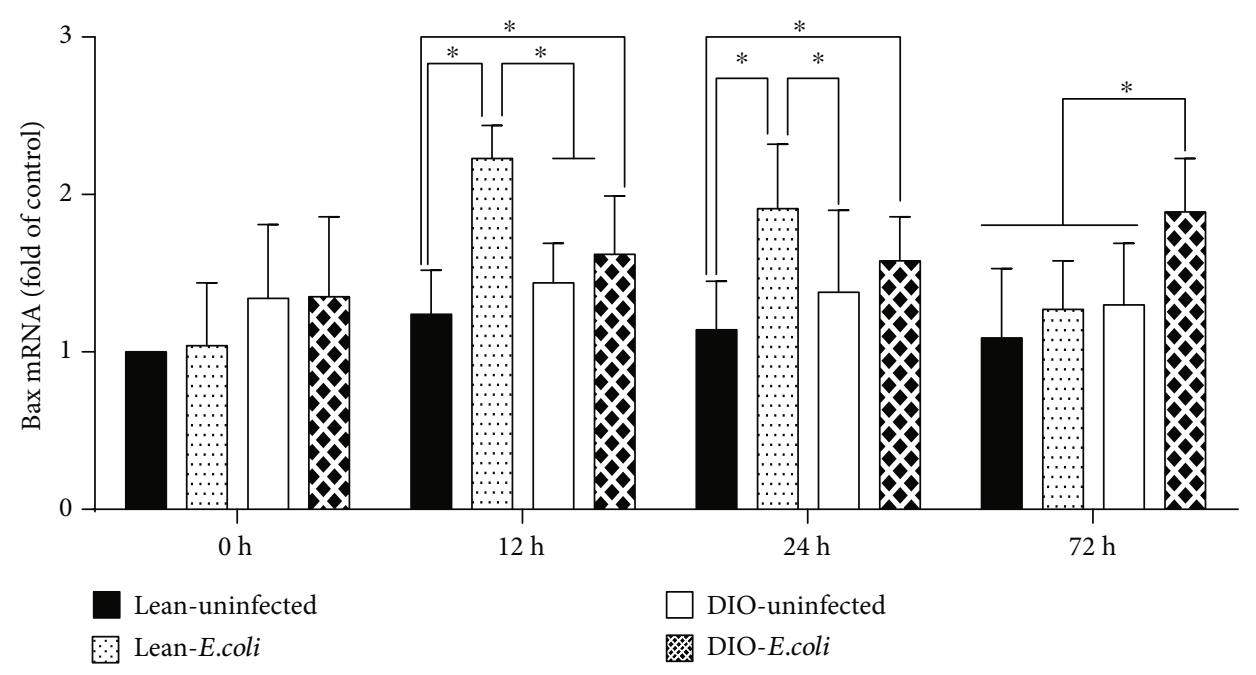

(a)

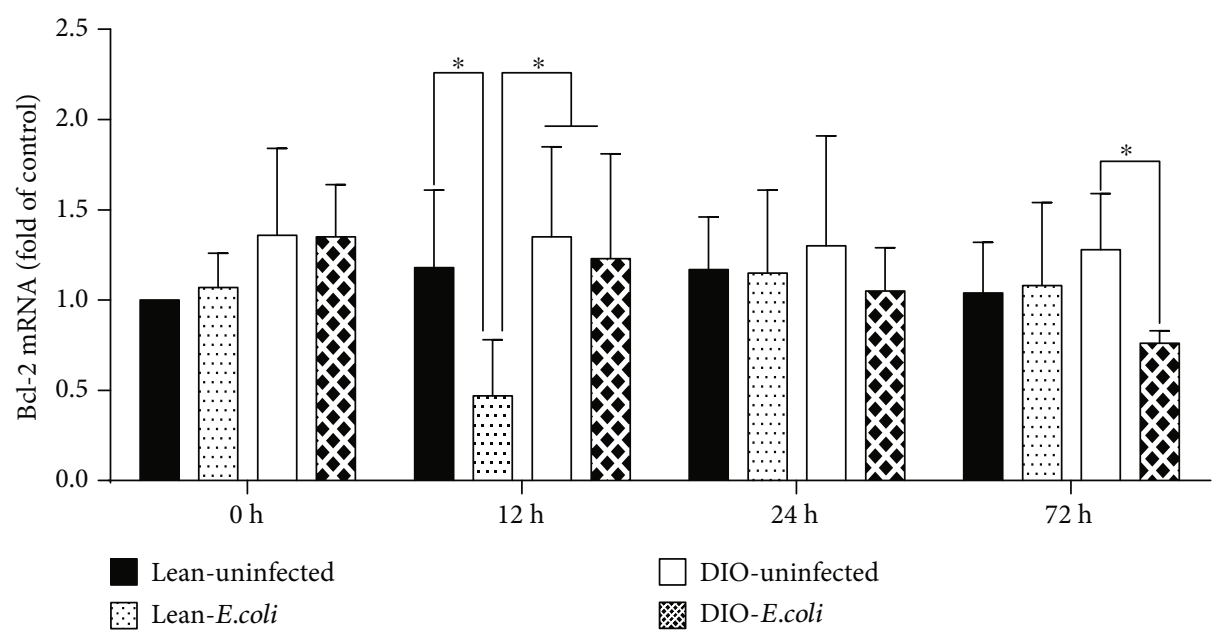

(b)

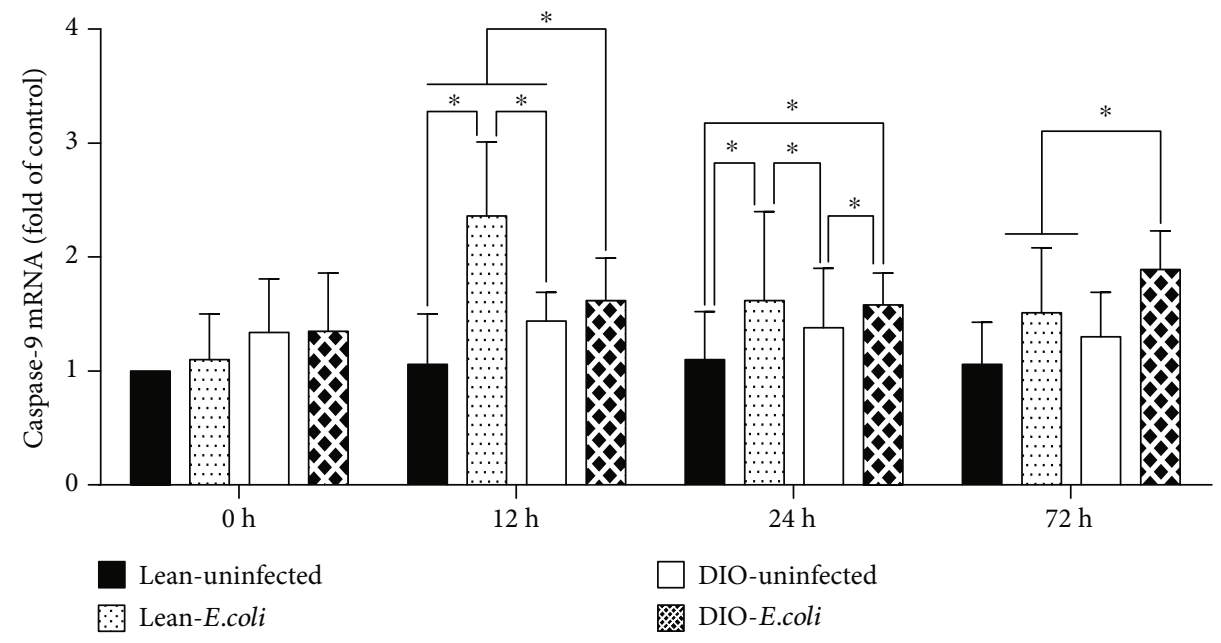

(c)

FIgURe 4: Continued. 


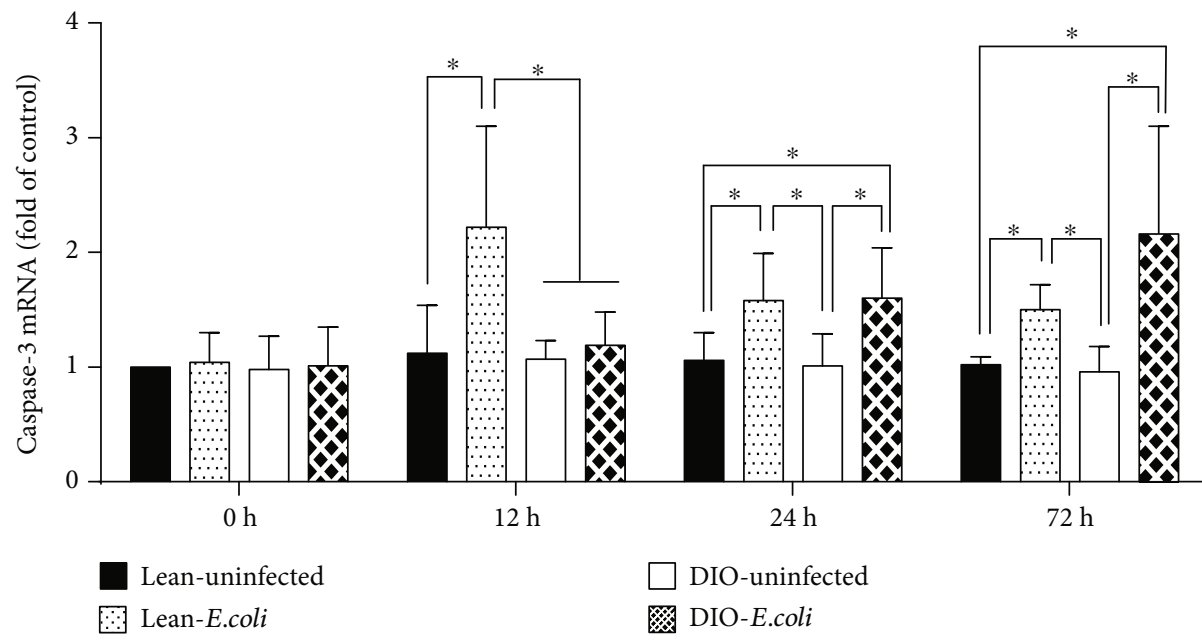

(d)
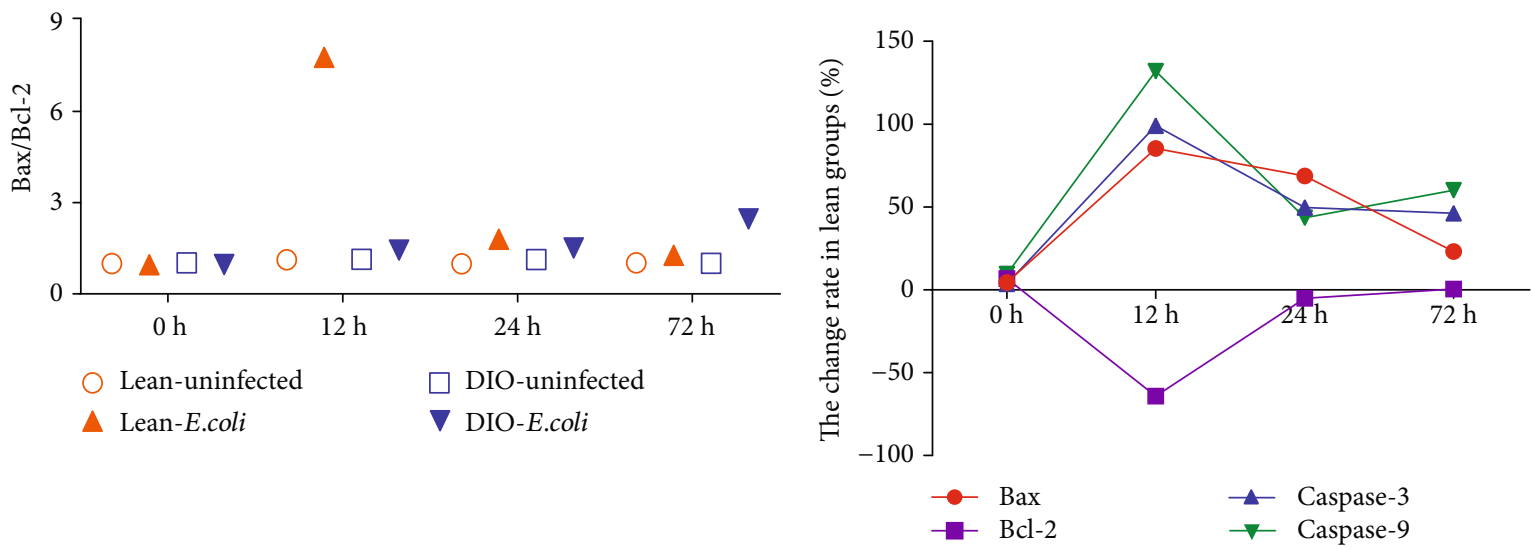

(e)

(f)

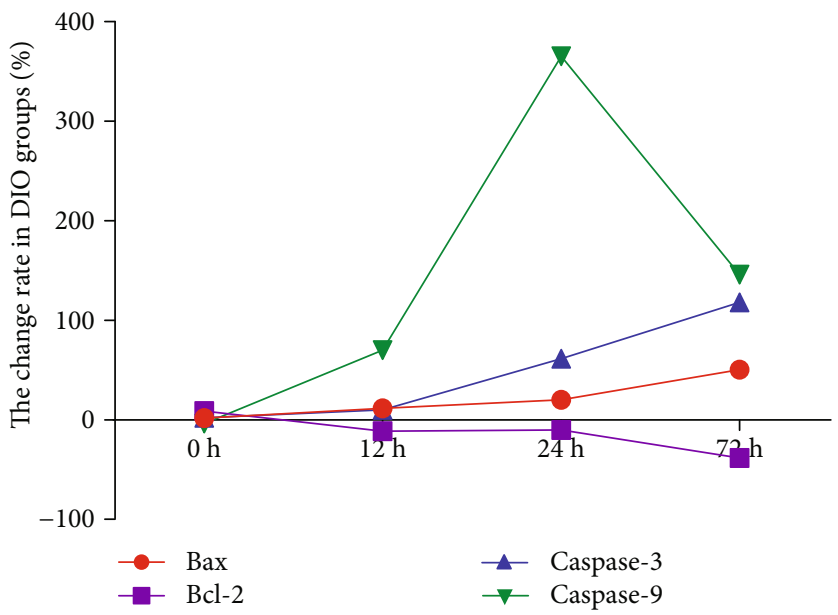

(g)

FIGURE 4: mRNA expressions of apoptotic factors associated with the mitochondrial pathway. (a-d) The mRNA levels of Bax, Bcl-2, caspase-3, and caspase-9 (fold of control). (e) The ratio of Bax/Bcl-2 mRNA. (f, g) The change rates of pulmonary apoptotic factor mRNA expression in the lean and DIO mice. ${ }^{*}$ The significant difference $(p<0.05)$.

cell apoptosis were detected in the lean- and DIO-E. coli groups in comparison to the uninfected groups in the present study. For further study, four important factors involved in the mitochondrial-mediated apoptotic pathway were detected. In the mitochondrial pathway, antiapoptotic and proapoptotic proteins interact with the mitochondria and 

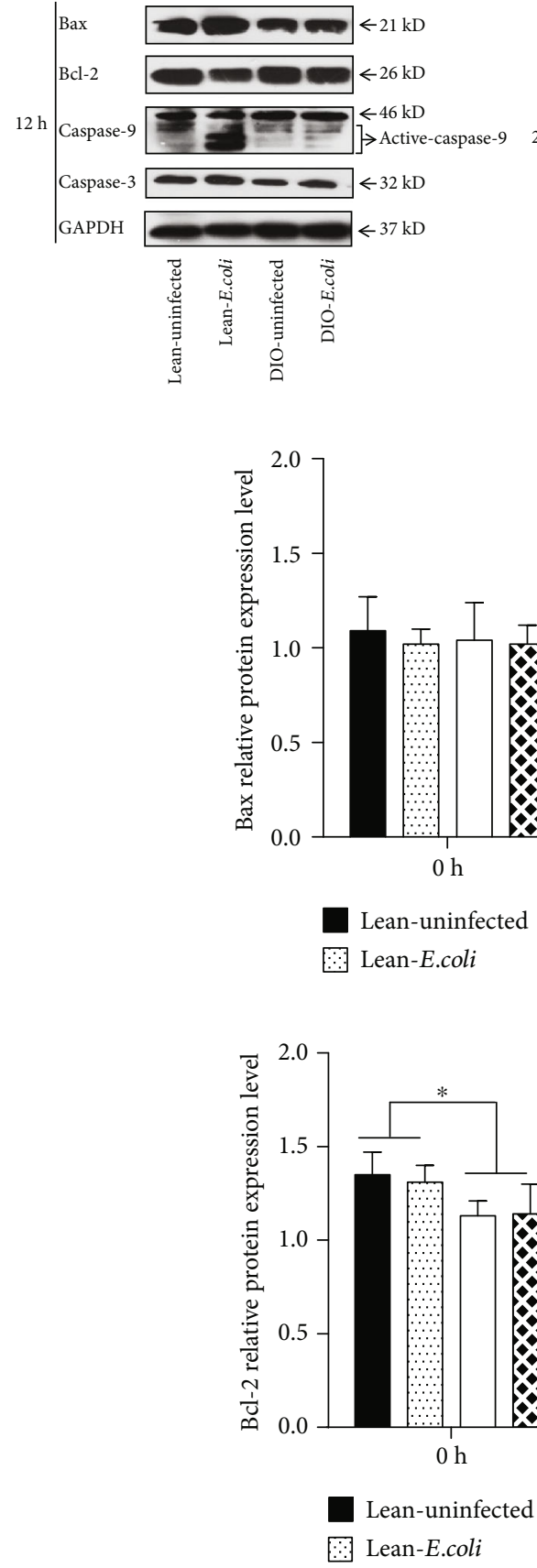

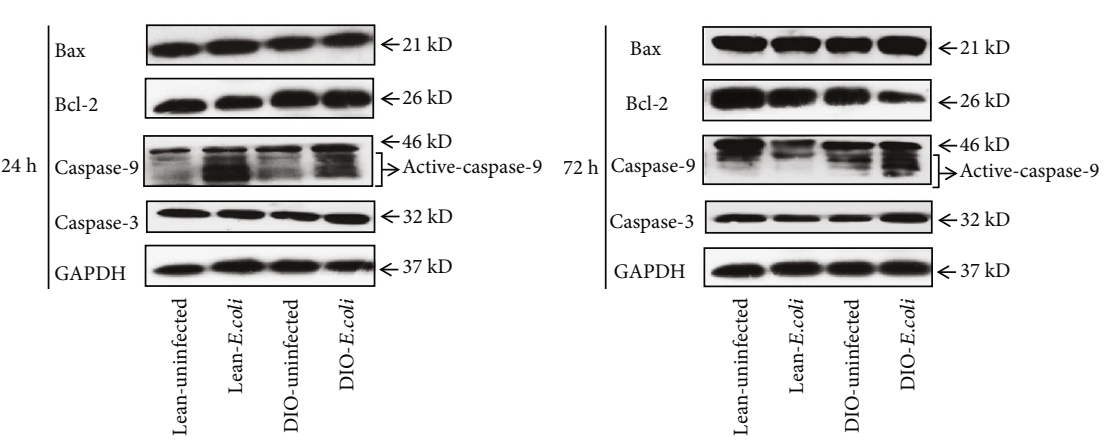

(a)

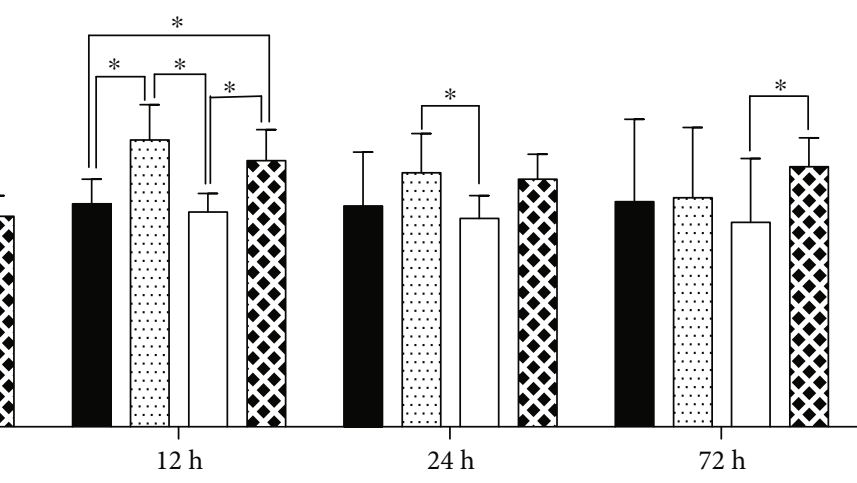

$\square$ DIO-uninfected

DIO-E.coli

(b)

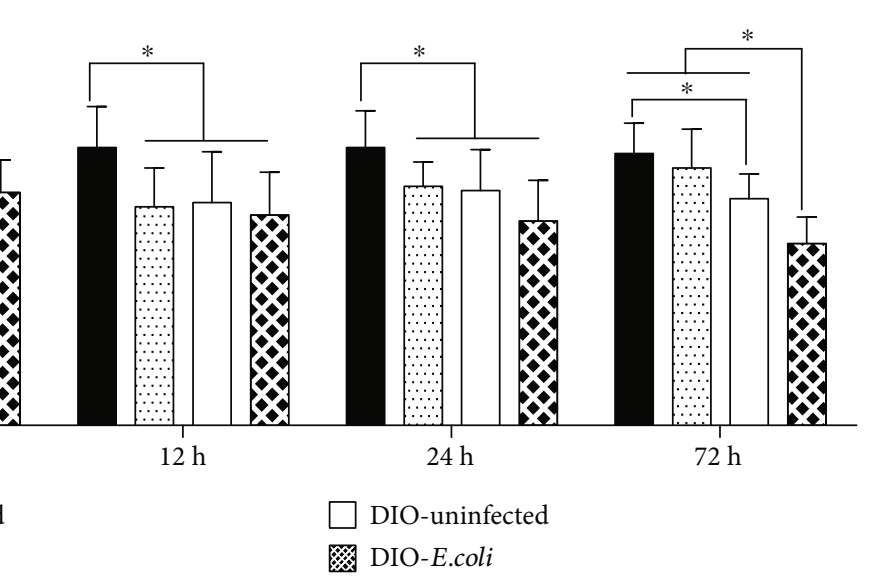

(c)

FIgure 5: Continued. 


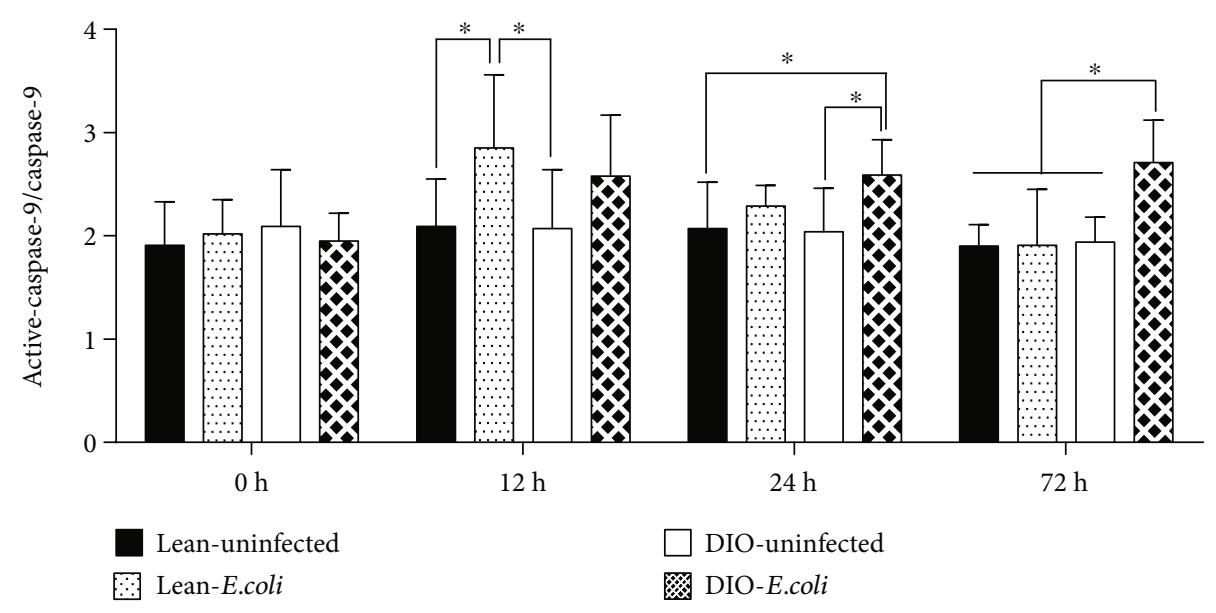

(d)

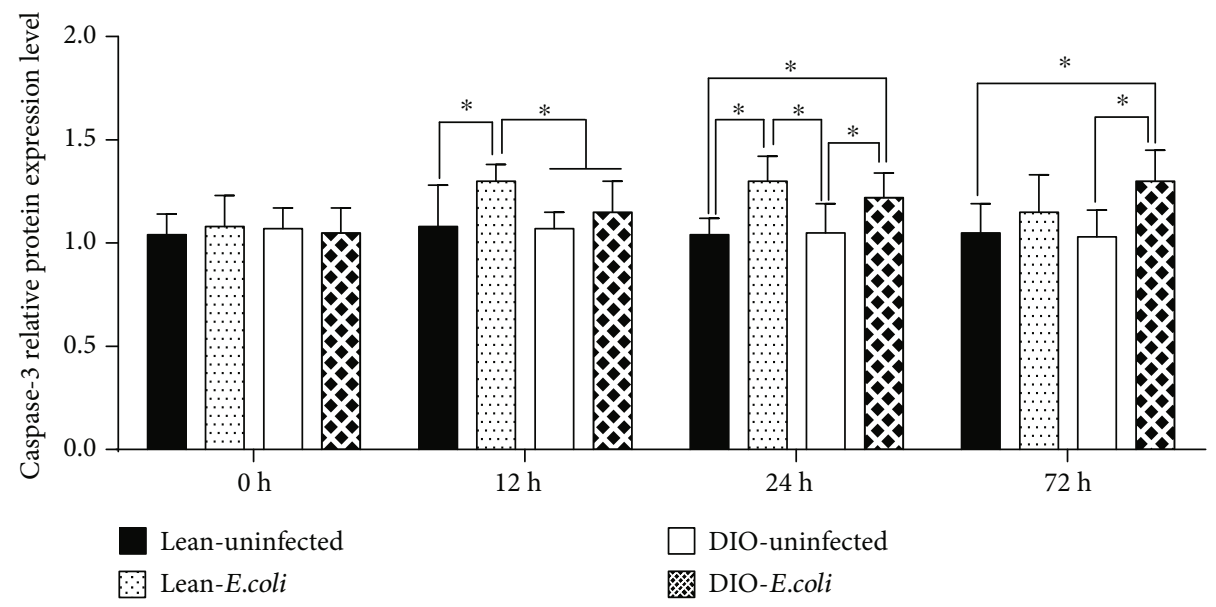

(e)
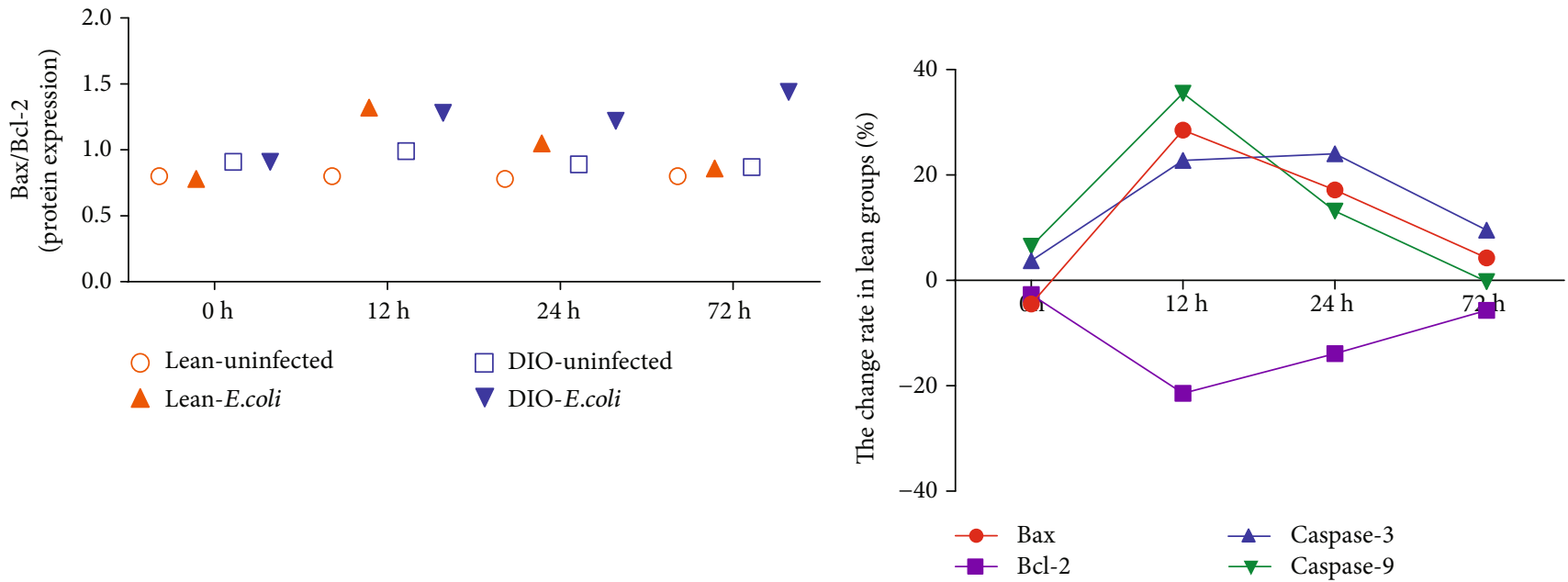

(f)

(g)

FIgURE 5: Continued. 


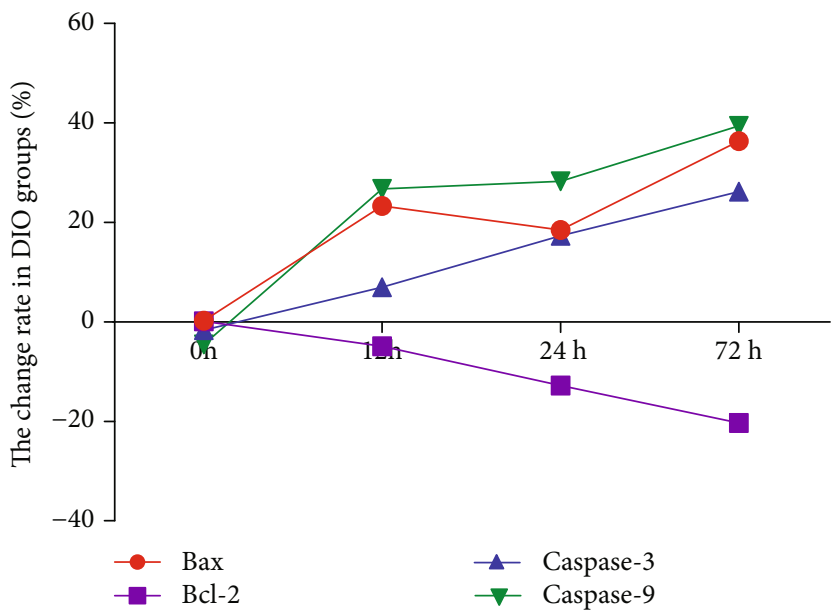

(h)

FIGURE 5: Protein expression of apoptotic factors associated with the mitochondrial pathway. (a) Representative western blot of protein expression. (b-e) The relative protein expression levels of Bax, Bcl-2, caspase-3, and caspase-9. (f) The ratio of Bax/Bcl-2 protein. $(\mathrm{g}, \mathrm{h})$ The change rate of pulmonary apoptotic factor protein expression in the lean and DIO mice. ${ }^{*}$ The significant difference $(p<0.05)$.

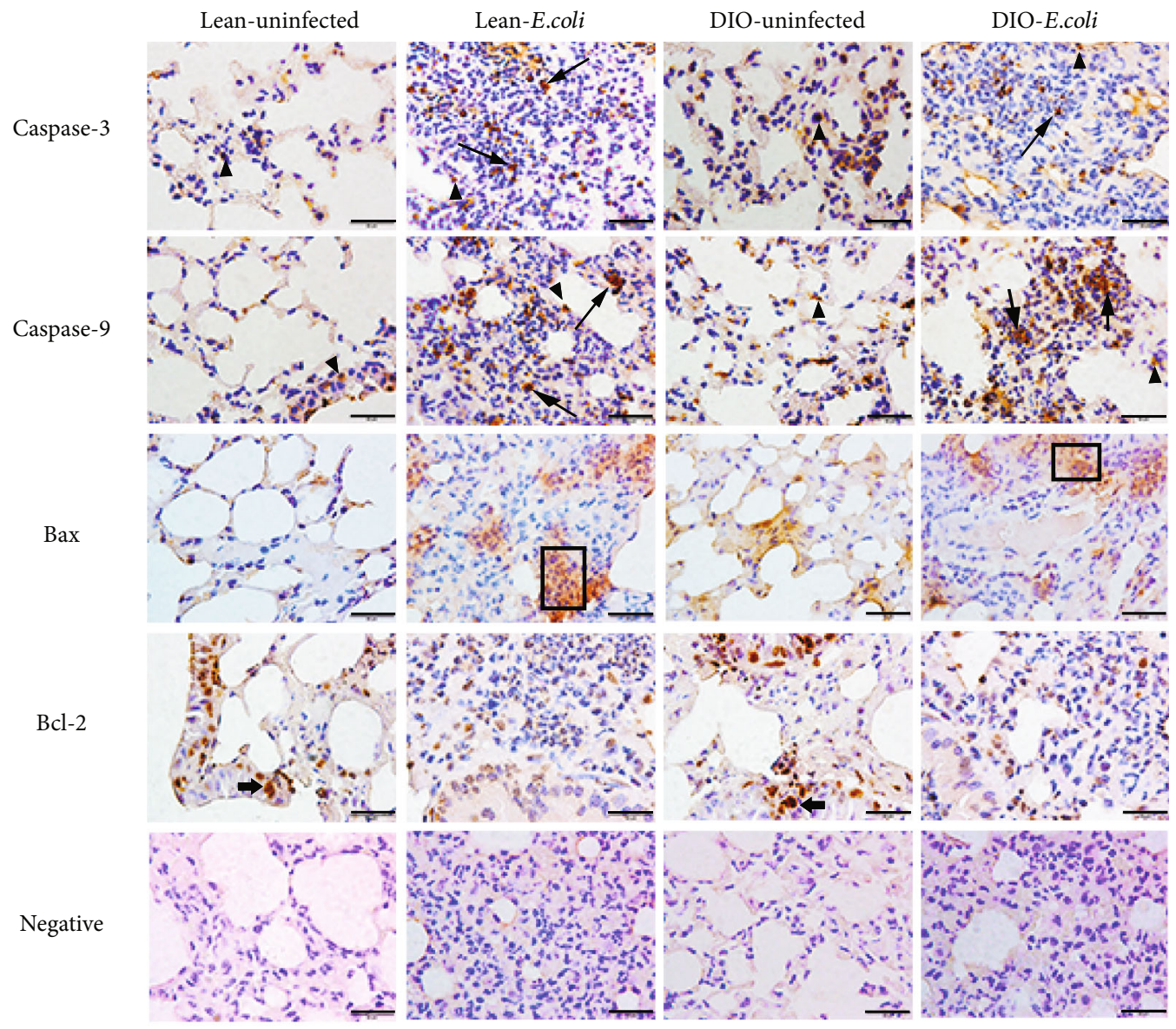

FIGURE 6: Representative immunohistochemistry staining of apoptotic proteins associated with the mitochondrial pathway at $12 \mathrm{~h}$. DAB. Scale bar $=20 \mu \mathrm{m}(1000 \mathrm{x})$. Positive caspase-3 or caspase- 9 proteins in neutrophils (long arrows). Positive caspase- 3 or caspase- 9 proteins in alveolar epithelia (arrowheads). Positive Bax proteins in the neutrophil-infiltrated areas (boxes). Positive Bcl-2 proteins in the epithelial cells of respiratory bronchioles (broad arrows). 
determine cell fate. The Bcl-2 family executes two opposing functions, including prosurvival proteins, such as Bcl-2, $\mathrm{Bcl}-\mathrm{w}$, and MCL-1, and proapoptotic proteins, such as Bax, $\mathrm{Bid}$, and Bad [34]. These proteins regulate the release of cytochrome $\mathrm{c}$ from the mitochondrial innermembrane space, forming apoptosome with apoptotic protease-activating factor 1 (Apaf-1), activating caspase-9, thus initiating a caspase cascade which ultimately leads cell apoptosis $[35,36]$. Researches on human monocytic U937 cells and epithelial HEp-2 cells showed that E. coli could induce apoptosis with an increased expression of Bax and a reduced expression of Bcl-2, which resulted in increased levels of released cytochrome c, caspase-3, and caspase-9 [37, 38]. In accordance with previous studies, after being infected with $E$. coli, the expressions of Bax, caspase-3, and caspase- 9 were significantly increased while $\mathrm{Bcl}-2$ was decreased in the infected groups.

Interestingly, the dramatic fold change in the percentage of cell apoptosis and the expression of apoptotic parameters were noted at $12 \mathrm{~h}$ or $24 \mathrm{~h}$ in the lean-E. coli group, whereas at $24 \mathrm{~h}$ or $72 \mathrm{~h}$ in the DIO-E. coli group. Meanwhile, the increased cytokine and adipocytokine levels were peaked at $12 \mathrm{~h}$ or $24 \mathrm{~h}$ in the lean mice, while these parameters continually increased along the infection time and peaked in the DIO mice at $72 \mathrm{~h}$ post infection [16]. These results indicated that the DIO mice may need longer time to respond to the inflammation than the lean mice. As it is well known, obesity is a medical condition, in which excess body fat increases body weight, resulting in more production of adipokines secreted by adipose tissue $[39,40]$. Leptin is the first discovered adipokine derived from adipocyte and can modulate neutrophil chemotaxis and ROS release [41]. Previous studies have reported that leptin showed antiapoptotic properties on neutrophil via the NF- $\kappa$ B and MEK1/2 MAPK pathways and led to delayed neutrophil apoptosis in vitro [42], inhibited thymic cells apoptosis through JAK-2 activation and IRS-1/PI3-K pathway in Wistar rats [43], and reduced degenerative nucleus pulposus cell apoptosis via promoting autophagy in vitro [44]. Other various adipokines, like vaspin, visfatin, and adiponectin, could inhibit apoptosis as well. Vaspin acts as a ligand for the cell-surface GRP78/VDAC complex inhibiting endothelial cell apoptosis. Visfatin shows antiapoptotic properties in TNF- $\alpha$-induced apoptosis in breast cancer cells and palmitate-induced apoptosis in pancreatic $\beta$-cells $[45,46]$. Adiponectin inhibits neutrophil apoptosis via activation of AMPK, PKB, ERK 1/2, and MAPK [47]. Therefore, obesity with increased levels of adipokines, like leptin and vaspin, might inhibit or delay cell apoptosis, which was accordance with our present results. Furthermore, cytokines and oxidative stress induced by inflammation are capable in triggering apoptosis [24, 27]. Following the infection, the proapoptotic effect of cytokines and oxidative stress was enhanced gradually, which counteracted the inhibited or delayed cell apoptotic effect executed by adipokines, resulting in a greater cell apoptotic rate in the DIO-E. coli group after $24 \mathrm{~h}$. These results also exhibited a significant role for neutrophil apoptosis in inflammation. Indeed, we found that, through immunohistochemistry staining (especially caspase-3-positive proteins), two types of cells, neutrophils and epithelial cells, underwent apoptosis during infection, but more importantly, adipokines could inhibit neutrophil constitutive or spontaneous apoptosis. Thus, the delayed or inhibited neutrophil apoptosis by DIO during infection was partly able to determine the infection process in the lung.

The mitochondrion is a double-membrane-bound organelle found in most eukaryotic organisms and acts as a source of chemical energy (adenosine triphosphate (ATP)) supply in cells [48]. By stimuli, the mitochondrion-mediated apoptosis can be initiated in a receptor-independent manner that increases mitochondrial inner membrane permeability accompanied by $\Delta \psi \mathrm{m}$ depolarization [49]. Stimulated by inflammation and infection, the proapoptosis protein bax and the antiapoptosis protein bcl-2 combined with ANT (adenine nucleotide translocator) or VDAC (voltage-dependent anion channel) competitively, and regulated the switch of the MPTP (mitochondria permeability transition pore). Once PT pores open, the mitochondrial transmembrane potential would dramatically decrease, leading the release of cytochrome $c$ and activating caspase- 9 gradually. Obese individuals have reduced oxidative phosphorylation (OXPHOS) gene expression and oxygen consumption and increased oxidative stress and ROS production, causing mitochondrial dysfunction [50]. In the present study, the percentage of pulmonary cells depolarized with the collapse of the $\Delta \psi \mathrm{m}$ was higher in the DIO mice than in the lean mice. On the contrary, obese Zucker rats displayed no difference in oxygen consumption, ATP synthesis, membrane potential, citrate synthase, and cytochrome c oxidase activities compared with lean Zucker rats [51]. After infection, the percentage significantly increased in both the lean- and DIO-E. coli groups, and the increase was more dramatic at 12 and $24 \mathrm{~h}$ in the lean-E. coli group but at $72 \mathrm{~h}$ in the DIO-E. coli group. These results suggested that $E$. coli pneumonia caused the $\Delta \psi \mathrm{m}$ change, by which the mitochondrion-mediated apoptotic pathway was activated in the lung of both the lean and DIO mice, but delayed in the latter.

For subcellular localization of these apoptotic factors, immunohistochemistry was performed. Bax should be in the membrane of mitochondria [52]. In the present duty, Bax-positive protein was detected as dispersive distribution in the lean- and DIO-E. coli groups. Identical to a previous report, Bcl-2 immunostaining is cytoplasmic and granular and restricted in normal bronchial epithelium to the basal epithelial layer or to some epithelial cells that are perpendicularly oriented to the basal lamina before infection [53], whereas, after infection, the Bcl-2 protein expression in the bronchial epithelial cells almost vanished and only a few Bcl-2 were noted in the neutrophil-infiltrated areas. Caspase- 3 and caspase- 9 were located in the mitochondria, cytosol, and nucleus in cells $[54,55]$. After being infected with E. coli, caspase- 3 and caspase- 9 proteins were mainly displayed in the cytoplasm of inflammatory cells and sloughed pulmonary epithelial cells in the neutrophil-infiltrated areas. Taken together, immunohistochemistry results suggested that these mitochondrion-mediated apoptotic proteins were mainly located in the neutrophil-infiltrated areas after infection. 


\section{Conclusions}

In conclusion, nasal infection with $E$. coli was able to establish bacterial pneumonia in mice. And after being infected with $E$. coli, both the lean and DIO mice exhibited increased percentages of apoptosis; decreased pulmonary $\Delta \psi \mathrm{m}$; upregulated expressions of Bax, caspase-3, and caspase- 9 mRNA and protein; and downregulated expression of Bcl-2. However, most impressively, almost all the above-mentioned parameters peaked at $12 \mathrm{~h}$ or $24 \mathrm{~h}$ in the lean-E. coli group but at $24 \mathrm{~h}$ or $72 \mathrm{~h}$ in the DIO-E. coli group. These results indicated that the DIO mice presented a delayed cell apoptosis in the acute pneumonia induced by E. coli infection through the mitochondrial apoptotic pathway. Meanwhile, the major cell exhibiting delayed apoptosis by obesity might be neutrophils in the mice with $E$. coli pneumonia. The observations reported here provide the foundation for further investigations on the relationship between obesity and bacterial infection.

\section{Data Availability}

The cytokine contents and oxidative stress data used to support the findings of this study have been deposited in the PubMed repository (10.1038/s41598-018-32420-3). The flow cytometry, qRT-PCR, and western bolt data used to support the findings of this study are included within the article.

\section{Conflicts of Interest}

The authors declare that there is no conflict of interest regarding the publication of this paper.

\section{Authors' Contributions}

Z. Z. and K. C. conceived the study; J. F., H. C., and F. W. designed the experiment; F. W. and K. C. interpreted the results and wrote the manuscript; G. S., Z. Y., and C. H. assisted with writing the manuscript. Y. Z., P. O., and Y. G. contributed the reagents/materials/analysis tools. All authors reviewed the manuscript. Fengyuan Wang, Zhicai Zuo, and Zhuangzhi Yang contributed equally to this work.

\section{Acknowledgments}

This work was supported by the program for the Natural Science Foundation of Science and Technology Department of Sichuan Province (2013NZ0032) and the program for Changjiang Scholars, the University Innovative Research Team (IRT 0848).

\section{References}

[1] C. M. Salome, G. G. King, and N. Berend, "Physiology of obesity and effects on lung function," Journal of Applied Physiology, vol. 108, no. 1, pp. 206-211, 2010.

[2] J. B. Kornum, M. Nørgaard, C. Dethlefsen et al., "Obesity and risk of subsequent hospitalisation with pneumonia," European Respiratory Journal, vol. 36, no. 6, pp. 1330-1336, 2010.
[3] V. F. Corrales-Medina, J. Valayam, J. A. Serpa, A. M. Rueda, and D. M. Musher, "The obesity paradox in communityacquired bacterial pneumonia," International Journal of Infectious Diseases, vol. 15, no. 1, pp. e54-e57, 2011.

[4] P. McLoughlin, "Obesity and lung disease: a toxic mix," Acta Physiologica, vol. 213, no. 4, pp. 756-757, 2015.

[5] H. Oliveros and E. Villamor, "Obesity and mortality in critically ill adults: a systematic review and meta-analysis," Obesity, vol. 16, no. 3, pp. 515-521, 2008.

[6] S. G. Memtsoudis, A. M. Bombardieri, Y. Ma, J. M. Walz, Y. L. Chiu, and M. Mazumdar, "Mortality of patients with respiratory insufficiency and adult respiratory distress syndrome after surgery: the obesity paradox," Journal of Intensive Care Medicine, vol. 27, no. 5, pp. 306-311, 2012.

[7] J. M. O’Brien Jr., G. S. Phillips, N. A. Ali, M. Lucarelli, C. B. Marsh, and S. Lemeshow, "Body mass index is independently associated with hospital mortality in mechanically ventilated adults with acute lung injury," Critical Care Medicine, vol. 34, no. 3, pp. 738-744, 2006.

[8] S. Elmore, "Apoptosis: a review of programmed cell death," Toxicologic Pathology, vol. 35, no. 4, pp. 495-516, 2007.

[9] K. Sinha, J. Das, P. B. Pal, and P. C. Sil, "Oxidative stress: the mitochondria-dependent and mitochondria-independent pathways of apoptosis," Archives of Toxicology, vol. 87, no. 7, pp. 1157-1180, 2013.

[10] M. L. Circu and T. Y. Aw, "Reactive oxygen species, cellular redox systems, and apoptosis," Free Radical Biology \& Medicine, vol. 48, no. 6, pp. 749-762, 2010.

[11] E. Yamamoto, Y. F. Dong, K. Kataoka et al., "Olmesartan prevents cardiovascular injury and hepatic steatosis in obesity and diabetes, accompanied by apoptosis signal regulating kinase-1 inhibition," Hypertension, vol. 52, no. 3, pp. 573-580, 2008.

[12] F. Pintus, G. Floris, and A. Rufini, "Nutrient availability links mitochondria, apoptosis, and obesity," Aging, vol. 4, no. 11, pp. 734-741, 2012.

[13] J. S. Messer, "The cellular autophagy/apoptosis checkpoint during inflammation," Cellular and Molecular Life Sciences, vol. 74, no. 7, pp. 1281-1296, 2017.

[14] C. V. Nogueira, T. Lindsten, A. M. Jamieson et al., "Rapid pathogen-induced apoptosis: a mechanism used by dendritic cells to limit intracellular replication of Legionella pneumophila," PLoS Pathogens, vol. 5, no. 6, p. e1000478, 2009.

[15] G. K. Singhera, T. S. Chan, J. Y. Cheng, T. Z. Vitalis, K. J. Hamann, and D. R. Dorscheid, "Apoptosis of viral-infected airway epithelial cells limit viral production and is altered by corticosteroid exposure," Respiratory Research, vol. 7, no. 1, 2006.

[16] F. Wang, Z. Zuo, K. Chen et al., "Histopathological changes caused by inflammation and oxidative stress in diet-inducedobese mouse following experimental lung injury," Scientific Reports, vol. 8, no. 1, p. 14250, 2018.

[17] T. Wan, G. Yuan, Y. Ren et al., "Diet-induced obese mice exhibit altered immune responses to acute lung injury induced by Escherichia coli," Obesity, vol. 24, no. 10, pp. 2101-2110, 2016.

[18] D. P. Arçari, W. Bartchewsky, T. W. dos Santos et al., "Antiobesity effects of yerba maté extract (Ilex paraguariensis) in high-fat diet-induced obese mice," Obesity, vol. 17, no. 12, pp. 2127-2133, 2009. 
[19] L. Zhang, "Mechanism of capsaicin and its receptor TRPV1 in obesity prevention," Army Medical University, 2006.

[20] T. Wan, G. Yuan, Z. Zuo, Z. Wang, Y. Jia, and Y. Ren, "Effects of obesity on lung inflammation of nonfatal pneumonia," Immunological Journal, no. 8, pp. 697-701, 2016.

[21] J. S. Lee, C. W. Frevert, G. Matute-Bello et al., "TLR-4 pathway mediates the inflammatory response but not bacterial elimination in E. coli pneumonia," American Journal of PhysiologyLung Cellular and Molecular Physiology, vol. 289, no. 5, pp. L731-L738, 2005.

[22] M. Baggiolini, A. Walz, and S. L. Kunkel, "Neutrophil-activating peptide-1/interleukin 8 , a novel cytokine that activates neutrophils," Journal of Clinical Investigation, vol. 84, no. 4, pp. 1045-1049, 1989.

[23] T. Kasama, Y. Miwa, T. Isozaki, T. Odai, M. Adachi, and S. L. Kunkel, "Neutrophil-derived cytokines: potential therapeutic targets in inflammation," Current Drug Targets. Inflammation and Allergy, vol. 4, no. 3, pp. 273-279, 2005.

[24] H. Zhao, "Extrinsic and intrinsic apoptosis signal pathway review," in Apoptosis \& Medicine, InTechOpen, 2012.

[25] K. Dalhoff, J. Braun, H. Kothe, M. Körber, M. Pein, and K. J. Wiessmann, "Oxidative metabolism of pulmonary phagocytes in acute pneumonia," Respiration, vol. 61, no. 3, pp. 144-149, 1994.

[26] T. M. Buttke and P. A. Sandstrom, "Oxidative stress as a mediator of apoptosis," Immunology Today, vol. 15, no. 1, pp. 7-10, 1994.

[27] H. P. Indo, M. Davidson, H. C. Yen et al., "Evidence of ROS generation by mitochondria in cells with impaired electron transport chain and mitochondrial DNA damage," Mitochondrion, vol. 7, no. 1-2, pp. 106-118, 2007.

[28] G. Matute-Bello and T. R. Martin, "Science review: apoptosis in acute lung injury," Critical Care, vol. 7, no. 5, pp. 355-358, 2003.

[29] F. Horn, A. M. R. Corrêa, N. L. Barbieri et al., "Infections with avian pathogenic and fecal Escherichia coli strains display similar lung histopathology and macrophage apoptosis," PLoS One, vol. 7, no. 7, p. e41031, 2012.

[30] J. H. J. Vernooy, M. A. Dentener, R. J. van Suylen, W. A. Buurman, and E. F. M. Wouters, "Intratracheal instillation of lipopolysaccharide in mice induces apoptosis in bronchial epithelial cells," American Journal of Respiratory Cell and Molecular Biology, vol. 24, no. 5, pp. 569-576, 2001.

[31] M. Kawasaki, K. Kuwano, N. Hagimoto et al., "Protection from lethal apoptosis in lipopolysaccharide-induced acute lung injury in mice by a caspase inhibitor," American Journal of Pathology, vol. 157, no. 2, pp. 597-603, 2000.

[32] J. J. Liu, C. W. Song, Y. Yue et al., "Quercetin inhibits LPS-induced delay in spontaneous apoptosis and activation of neutrophils," Inflammation Research, vol. 54, no. 12, pp. 500-507, 2005.

[33] F. Loison and H. Luo, "Neutrophil apoptosis and its involvement in inflammation and infection," Apoptosis Modern Insights into Disease from Molecules to Man, Science Publishers, 2010.

[34] M. J. Roy, A. Vom, P. E. Czabotar, and G. Lessene, "Cell death and the mitochondria: therapeutic targeting of the BCL-2 family-driven pathway," British Journal of Pharmacology, vol. 171, no. 8, pp. 1973-1987, 2014.

[35] S. B. Bratton and G. S. Salvesen, "Regulation of the Apaf-1caspase-9 apoptosome," Journal of Cell Science, vol. 123, no. 19, pp. 3209-3214, 2010.
[36] C. X. Wang and R. J. Youle, "The role of mitochondria in apoptosis," European Journal of Cancer, vol. 41, no. 1, pp. 11-22, 2008.

[37] J. H. Wang, B. Yu, P. He, and X. Bai, "Roles of Bcl-2 family members, PI3K and NF- $\kappa$ B pathways in Escherichia coliinduced apoptosis in human monocytic U937 cells," World Journal of Microbiology and Biotechnology, vol. 27, no. 8, pp. 1827-1838, 2011.

[38] N. L. Jones, A. Islur, R. Haq et al., "Escherichia coli Shiga toxins induce apoptosis in epithelial cells that is regulated by the Bcl-2 family," American Journal of Physiology-Gastrointestinal and Liver Physiology, vol. 278, no. 5, pp. G811-G819, 2000.

[39] Organization WH, Obesity and Overweight, 2017, https:// www.who.int/gho/ncd/risk_factors/overweight_text/en/.

[40] M. T. Azar Sharabiani, R. Vermeulen, C. Scoccianti et al., "Immunologic profile of excessive body weight," Biomarkers, vol. 16, no. 3, pp. 243-251, 2011.

[41] F. Caldefiechezet, A. Poulin, A. Tridon, B. Sion, and M. Vasson, "Leptin: a potential regulator of polymorphonuclear neutrophil bactericidal action?," Journal of Leukocyte Biology, vol. 69, no. 3, pp. 414-418, 2001.

[42] Z. Sun, S. Dragon, A. Becker, and A. S. Gounni, "Leptin inhibits neutrophil apoptosis in children via ERK/NF- $\kappa$ Bdependent pathways," PLoS One, vol. 8, no. 1, p. e55249, 2013.

[43] E. Mansour, F. G. Pereira, E. P. Araújo et al., "Leptin inhibits apoptosis in thymus through a janus kinase-2-independent, insulin receptor substrate-1/phosphatidylinositol-3 kinasedependent pathway," Endocrinology, vol. 147, no. 11, pp. 5470-5479, 2006.

[44] W. Zhang, Z. L. Li, and Q. Zhang, "Leptin inhibits apoptosis of nucleus pulposus cells via promoting autophagy," European Review for Medical and Pharmacological Sciences, vol. 22, pp. 786-795, 2018.

[45] Z. Gholinejad, N. Kheiripour, M. Nourbakhsh et al., "Extracellular NAMPT/Visfatin induces proliferation through ERK1/2 and AKT and inhibits apoptosis in breast cancer cells," Peptides, vol. 92, pp. 9-15, 2017.

[46] G. Xu, C. Shi, C. Ji et al., "Expression of microRNA-26b, an obesity-related microRNA, is regulated by free fatty acids, glucose, dexamethasone and growth hormone in human adipocytes," Molecular Medicine Reports, vol. 10, no. 1, pp. 223-228, 2014.

[47] A. Rossi and J. M. Lord, "Adiponectin inhibits neutrophil apoptosis via activation of AMP kinase, PKB and ERK 1/2 MAP kinase," Apoptosis, vol. 18, no. 12, pp. 1469-1480, 2013.

[48] N. A. W. B. Campbell and R. J. Heyden, Biology Exploring Life, Pearson Prentice Hall, Boston, Massachusetts, 2006.

[49] R. Taneja, J. Parodo, S. H. Jia, A. Kapus, O. D. Rotstein, and J. C. Marshall, "Delayed neutrophil apoptosis in sepsis is associated with maintenance of mitochondrial transmembrane potential and reduced caspase- 9 activity," Critical Care Medicine, vol. 32, no. 7, pp. 1460-1469, 2004.

[50] J. C. Bournat and C. W. Brown, "Mitochondrial dysfunction in obesity," Current Opinion in Endocrinology, Diabetes and Obesity, vol. 17, no. 5, pp. 446-452, 2010.

[51] M. Flamment, M. Arvier, Y. Gallois et al., "Fatty liver and insulin resistance in obese Zucker rats: no role for mitochondrial dysfunction," Biochimie, vol. 90, no. 9, pp. 1407-1413, 2008.

[52] R. J. M. Natalino, C. B. G. Antoneli, K. de Cássia Braga Ribeiro, A. H. J. F. M. Campos, and F. A. Soares, "Immunohistochemistry of apoptosis-related proteins in retinoblastoma," 
Pathology - Research and Practice, vol. 212, no. 12, pp. 11441150, 2016.

[53] V. Masciullo and A. Giordano, "Immunohistochemistry of BCL-2 Gene Expression in Lung Carcinoma," in Handbook of Immunohistochemistry and In Situ Hybridization of Human Carcinomas, vol. 1, pp. 223-229, Elsevier, 2002.

[54] S. Yuan, X. Yu, J. M. Asara, J. E. Heuser, S. J. Ludtke, and C. W. Akey, "The holo-apoptosome: activation of procaspase- 9 and interactions with caspase-3," Structure, vol. 19, no. 8, pp. 1084-1096, 2011.

[55] B. Zhivotovsky, A. Samali, A. Gahm, and S. Orrenius, "Caspases: their intracellular localization and translocation during apoptosis," Cell Death \& Differentiation, vol. 6, no. 7, pp. 644-651, 1999. 


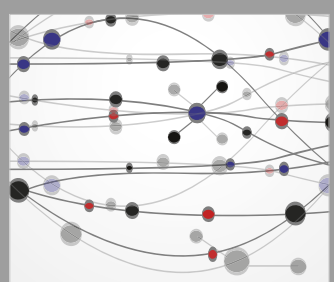

The Scientific World Journal
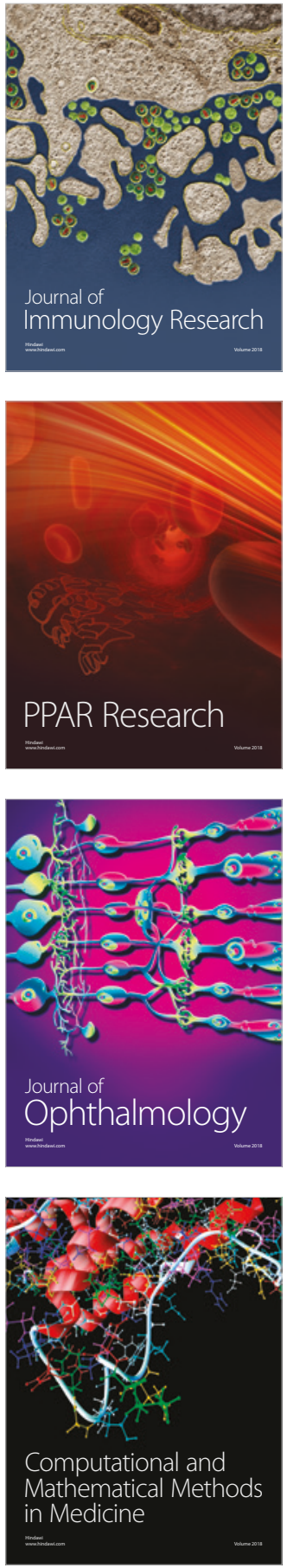

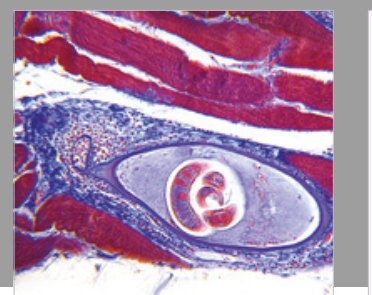

Gastroenterology Research and Practice

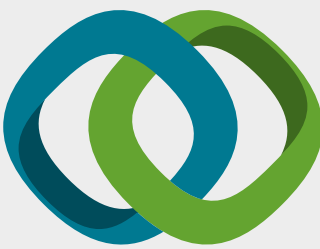

\section{Hindawi}

Submit your manuscripts at

www.hindawi.com
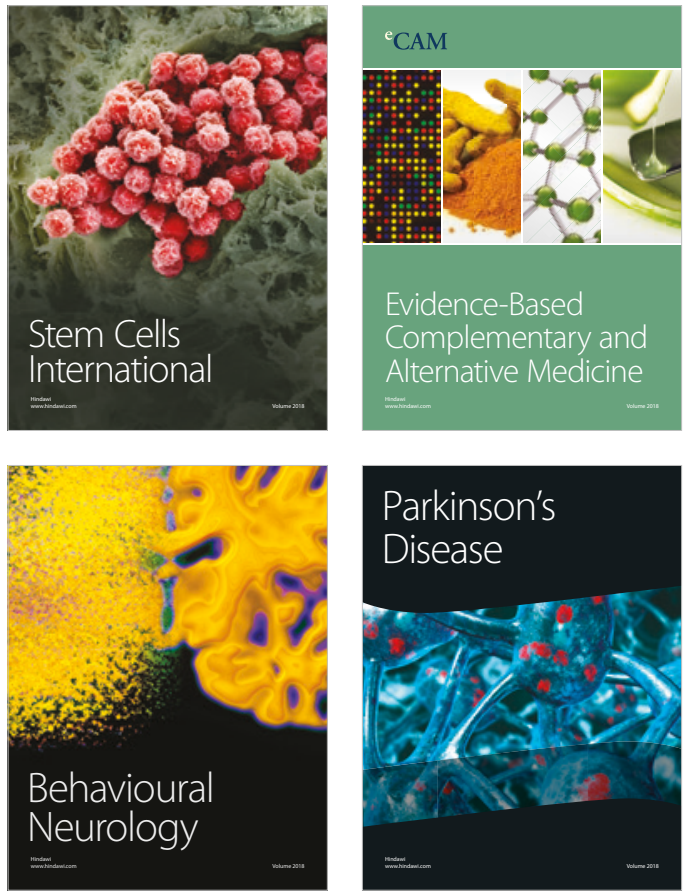

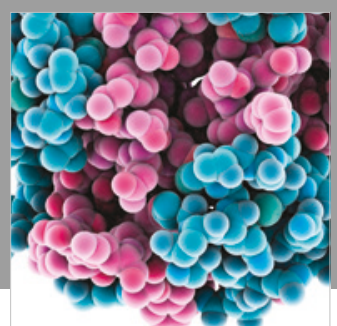

ournal of

Diabetes Research

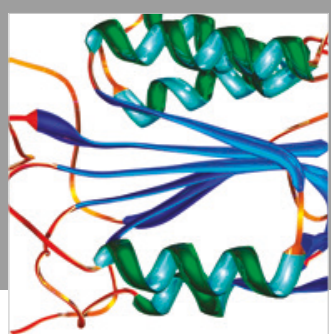

Disease Markers
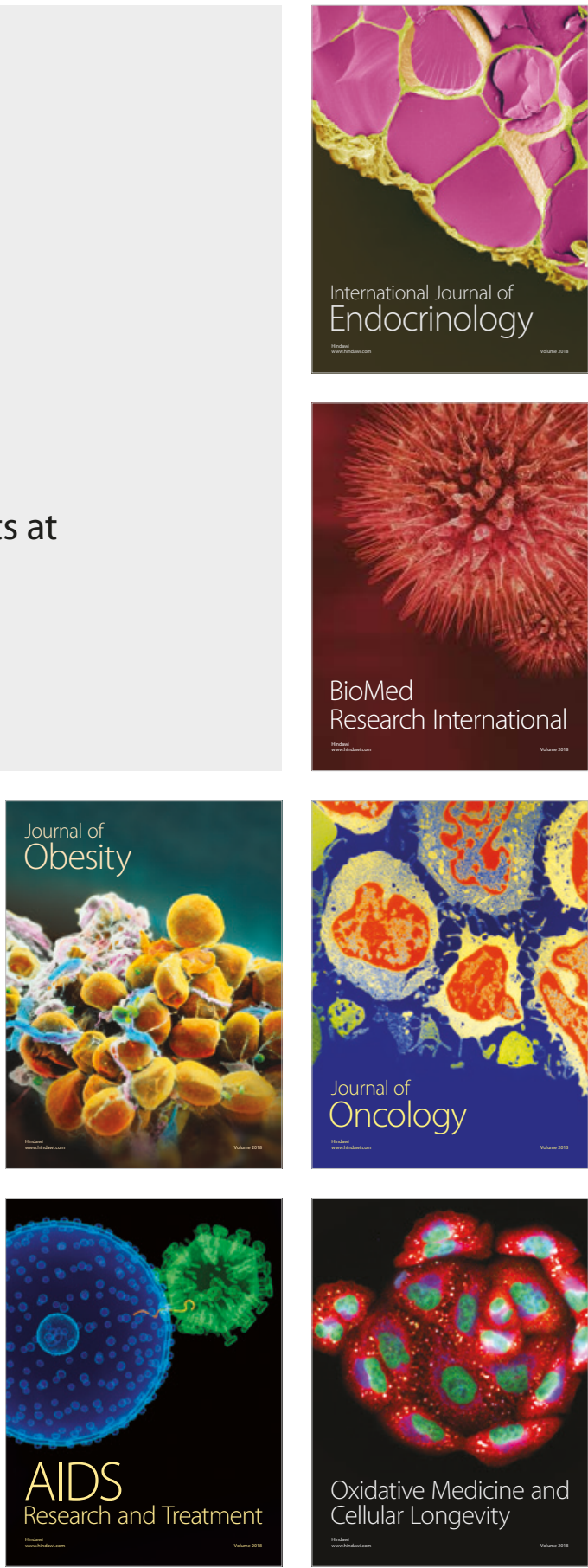